\title{
A Glutamic Acid-Containing Mucopolysaccharide from a Marine Pseudomonas
}

\author{
Wanchai Worawattanamateekul,* Masahiko Hasui,* and Koichi Okutani* \\ (Received April 30, 1992)
}

\begin{abstract}
A marine strain of Pseudomonas (No. 42), which was originally isolated from seawater, produced an acidic mucopolysaccharide containing glutamic acid when grown on seawater agar medium containing sucrose. The polysaccharide was extracted with $1 \%$ phenol solution and purified by the addition of ethanol, followed by precipitation with Cetavlon and DEAE-cellulose chromatography. This polysaccharide preparation was homogeneous in both ultracentrifugal and electrophoretic analyses. This polysaccharide was composed of glucosamine, glucuronic acid, and glutamic acid.
\end{abstract}

Many microorganisms are known to produce mucopolysaccharides such as sugar moieties of lipopolysaccharides and cell wall polysaccharides. However, there are only a few reports on nonconjugated extracellular mucopolysaccharides produced by microorganisms. ${ }^{1-5)}$

In the course of screening for extracellular polysaccharide-producing bacteria from marine environments, we isolated a strain, designated No. 42, which was identified as Pseudomonas sp. This bacterium was found to produce an extracellular acidic mucopolysaccharide containing glutamic acid. As an amino acid-containing polysaccharide we have already reported an alanine-containing polysaccharide from a marine pseudomonad." It should be noted that some lipopolysaccharides also contain lysine and $N$ (2-hydoxyethyl)-D-alanine. ${ }^{6,7)}$

This paper describes the isolation and characterization of the glutamic acid-containing mucopolysaccharide elaborated by a marine bacterium strain No. 42, together with studies of the identification of the bacterium.

\section{Materials and Methods}

\section{Bacterial Strain}

A bacterial strain No. 42, was isolated from the seawater of the Seto Inland Sea, Japan. The seawater medium used for bacterial isolation and polysaccharide production contained $30 \mathrm{~g}$ of sucrose, $5 \mathrm{~g}$ of peptone, $1 \mathrm{~g}$ of yeast extract, and $15 \mathrm{~g}$ of agar per $l$ of seawater. Taxonomic studies were carried out using the methods de- scribed previously. ${ }^{87}$

\section{Isolation of a Polysaccharide}

An actively growing culture was inoculated in $10 \mathrm{~m}$ l of the seawater medium (as above, but without agar) which was incubated for $24 \mathrm{~h}$ at $28^{\circ} \mathrm{C}$ with shaking. This $10 \mathrm{ml}$ culture was then poured onto a seawater agar plate $(18 \times 26 \mathrm{~cm})$. After incubation for 3 days at $25^{\circ} \mathrm{C}$, mucoid growth was scraped from the agar surface using $1 \%$ phenol solution. After stirring the mucoid material vigorously, bacterial cells were removed by filtration through a Whatman GFF filter after addition of Celite 545. To the clear filtrate, 2 volumes of ethanol were added. The precipitated polysaccharide was collected by filtration, dissolved in water, and reprecipitated with $5 \%$ cetyltrimethylammonium bromide solution (Cetavlon). ${ }^{\text {s }}$ The precipitates were collected by filtration and dissolved in $4 \mathrm{M} \mathrm{NaCl}$ solution, to which 2 volumes of ethanol were added. The precipitates thus obtained were dissolved in water and the resulting solution was dialyzed against deionized water, followed by freeze-drying.

Further fractionation and purification were achieved by chromatography on a DEAE-cellulose column $(2.3 \times 22.5 \mathrm{~cm})$ using stepwise elution with $0.01 \mathrm{M}$ phosphate buffer (pH 7.0) containing $0-2.0 \mathrm{M} \mathrm{NaCl}$. Fractions were monitored by phenol-sulfuric acid method. ${ }^{\circ)}$ Sugarcontaining fractions were combined and dialyzed against deionized water, followed by freezedrying.

O-Deacetylation of the polysaccharide was

* Faculty of Agriculture, Kagawa University, Miki, Kida, Kagawa 761-07, Japan (W. Worawattanama-

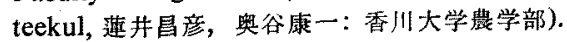


achieved by treatment with $0.1 \mathrm{M} \mathrm{NaOH}$ solution for $4 \mathrm{~h}$ at $30^{\circ} \mathrm{C}$, followed by dialysis and freezedrying.

\section{Analytical Methods}

Cell morphology was observed by electron microscopy. Negatively stained preparations were examined with a Hitachi HU-12A electron microscope.

Optical rotations were measured with a JASCO $\mathrm{J}-20 \mathrm{C}$ spectropolarimeter. Ultracentrifugal analysis was performed with a Hitachi 282 analytical ultracentrifuge.

Electrophoresis was performed on cellulose acetate strips (Sartorius 11200, $57 \times 145 \mathrm{~mm}$ ) in $0.2 \mathrm{M}$ calcium acetate buffer (pH 7.5) or in $0.05 \mathrm{M}$ sodium borate buffer ( $\mathrm{pH}$ 9.4). The strips were stained either with $0.1 \%$ Alcian Blue in $10 \%$ acetic acid ${ }^{10)}$ or alkaline silver nitrate reagent. ${ }^{113}$

The ${ }^{1} \mathrm{H}$ NMR spectrum was obtained with a JEOL JNM GSX 500 spectrometer $\left({ }^{1} \mathrm{H} 500 \mathrm{MHz}\right)$ at $31^{\circ} \mathrm{C}$. The sample was dissolved in $\mathrm{D}_{2} \mathrm{O}$ containing DSS as the internal standard.

Paper chromatography was carried out by the descending method on Whatman No. 1 paper (for analytical use) or Whatman 3MM paper (for preparative use) with ethyl acetate-acetic acid-formic acid-water $(18: 3: 1: 4)$ as the solvent. Sugars were detected either with alkaline silver nitrate, $p$-anisidine hydrochloride, or ninhydrin reagents. Mobilities of sugar components are expressed relative to D-glucose $\left(\mathbf{R}_{\mathrm{g} 1_{0}}\right)$.

Sugars were analyzed with a Hitachi 655 HPLC equipped with an RI detector on a Wakopak WBT 130E column (Wako Pure Chemicals, $7.8 \times 300 \mathrm{~mm}$ ) using water as a mobile phase at $60^{\circ} \mathrm{C}$ at a flow rate of $0.5 \mathrm{~m} / / \mathrm{min}$. The average molecular weight of the polysaccharide was determined with a Hitachi 655 HPLC equipped with an RI detector on an Asahipak GFA $7 \mathrm{M}$ column (Asahi Chemicals, $7.6 \times 500 \mathrm{~mm}$ ). For minimizing the association effect of the polysaccharide solution, aqueous $0.1 \mathrm{M} \mathrm{NaCl}$ solution was used as a mobile phase at $30^{\circ} \mathrm{C}$ and at a flow rate of $0.4 \mathrm{~m} / / \mathrm{min}$. A Shodex Standard Kit P-82 (Showa Denko, M. W. $=0.58 \times 10^{4}$ $-85 \times 10^{4}$ ) was used for calibration of the molecular size.

\section{Component Analyses}

For the analyses of components, the polysaccharide was hydrolyzed with $2 \mathrm{M}$ trifluoroacetic acid (TFA) for $12 \mathrm{~h}$ at $100^{\circ} \mathrm{C}$ in a sealed glass tube. After evaporation to dryness, the hydrolyzates were analyzed by paper chromatography, electrophoresis and HPLC. For the analyses of amino acids and amino sugars, the polysaccharide was hydrolyzed with $4 \mathrm{~N} \mathrm{HCl}$ for $12 \mathrm{~h}$ at $100^{\circ} \mathrm{C}$, followed by concentration to dryness over $\mathrm{P}_{2} \mathrm{O}_{5}$ and $\mathrm{NaOH}$ in vacuo. The residue was analyzed by paper chromatography, electrophoresis, HPLC, and with a Hitachi L-8500 amino acid analyzer.

Sulfate contents were determined with a Shimadzu HIC-6A ion chromatograph using a Shimpack IC-Al column $(4.6 \times 100 \mathrm{~mm})$ and a conductivity detector using $2.5 \mathrm{~mm}$ phthalic acid containing $2.4 \mathrm{~mm}$ Tris (hydroxymethyl) aminomethane ( $\mathrm{pH} 4.0$ ) at $40^{\circ} \mathrm{C}$ after hydrolysis of the polysaccharide with $2 \mathrm{M}$ TFA for $12 \mathrm{~h}$ at $100^{\circ} \mathrm{C}$.

Uronic acid contents were determined by the carbazole-sulfuric acid method. ${ }^{22}$ Protein contents were determined by the method of Lowry et al. ${ }^{13)} \quad$ Nucleic acid contents were estimated from UV absorption at $260 \mathrm{~nm}$. Pyruvate was determined by ion chromatography as follows: the polysaccharide was hydrolyzed with $0.05 \mathrm{~N}$ $\mathrm{H}_{2} \mathrm{SO}_{4}$ for $1 \mathrm{~h}$ at $100^{\circ} \mathrm{C}$, and the hydrolyzates were analyzed on a Shimpack IC-101H column (Shimadzu, $7.9 \times 300 \mathrm{~mm}$ ) at $50^{\circ} \mathrm{C}$ with $5 \mathrm{~mm}$ perchloric acid as a mobile phase using a Shimadzu HIC-6A ion chromatograph equipped with a UV detector (at $210 \mathrm{~nm}$ ).

\section{Periodate Oxidation and Smith Degradation}

A solution of the polysaccharide $(50 \mathrm{mg})$ in deionized water $(25 \mathrm{~m} l)$ was oxidized with $0.02 \mathrm{M}$ sodium metaperiodate $(25 \mathrm{ml})$ for 3 days at $5^{\circ} \mathrm{C}$ in the dark. After the excess of periodate was decomposed with ethylene glycol $(12.5 \mathrm{ml})$, the oxidized polymer was reduced with sodium borohydride $(250 \mathrm{mg})$ overnight at room temperature, After the excess of borohydride was decomposed by acidifying with acetic acid, the product was dialyzed against deionized water, followed by freeze-drying $(40 \mathrm{mg})$. Smith hydrolysis of the periodate oxidized and reduced polymer $(20 \mathrm{mg})$ was effected with $0.5 \mathrm{M}$ TFA for $12 \mathrm{~h}$ at $25^{\circ} \mathrm{C}$ to yield the polyol.

\section{Results and Discussion}

Strain No. 42 is a Gram negative straight rod $(0.5-0.6 \times 1.8-2.6 \mu \mathrm{m})$ as shown in Fig. 1. It is asporogenous, motile by means of a polar flagellum, and aerobic. It grows on OF medium 


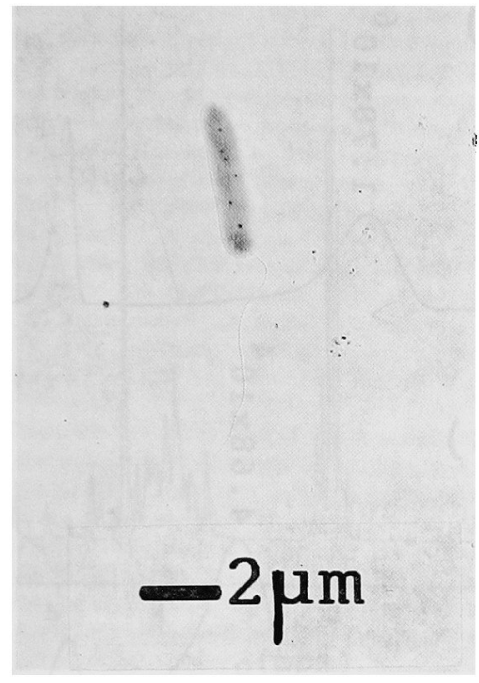

Fig. 1. Electron micrograph of bacterial strain No. 42.

oxidatively and produces oxidase. These features together with biochemical characteristics listed in Table 1 were reminiscent of Pseudomonas according to general bacteriology manuals. ${ }^{14,15)}$ The biochemical profiles did not fit well with any of the described species. ${ }^{16-18)}$ Since this isolate grows well on a medium prepared with seawater and can grow at $7 \% \mathrm{NaCl}$, we consider this isolate to be a marine strain of Pseudomonas.

\section{Preparation of the Polysaccharide}

Purification of the polysaccharide by DEAEcellulose column chromatography showed that most of the carbohydrate was eluted with $0.4 \mathrm{M}$ $\mathrm{NaCl}$ solution (Table 2). The polysaccharide preparation thus obtained was used through this study.

The purified polysaccharide preparation was homogeneous in both ultracentrifugal (Fig. 2) and electrophoretic analyses. It was a colorless powder with specific optical rotation $[\alpha]_{\mathrm{D}}=+5.0^{\circ}$ ( $c 0.3$, water) and the approximate sedimentation coefficient of $1.8 \mathrm{~S}$. The molecular weight was estimated to be $1.78 \times 10^{6}$ (Fig. 3A).

\section{Component Analysis of the Polysaccharide}

The ${ }^{1} \mathrm{H}$ NMR spectrum of the polysaccharide (Fig. 4) revealed methyl signals of $N$-acetylated groups at $\delta_{\mathrm{H}} 2.11,2.08,2.06$, and 2.00, indicating the presence of $N$-acetylated amino sugar re-

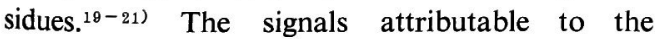
methyl protons of $O$-acetyl groups were observed
Table 1. Characteristics of the isolate

\begin{tabular}{|c|c|}
\hline Characteristics & Isolate \\
\hline Indole production & - \\
\hline Oxidase (Kovac's) & + \\
\hline Gram stain & - \\
\hline Spores & - \\
\hline Motility $\left(25^{\circ} \mathrm{C}\right)$ & + \\
\hline Glucose OF medium & $\mathrm{O}$ \\
\hline Lysine decarboxylase & - \\
\hline Arginine dihydrolase & - \\
\hline Deoxyribonuclease & + \\
\hline Catalase & + \\
\hline \multicolumn{2}{|l|}{ Hydrolysis of: } \\
\hline Gelatin & - \\
\hline Starch & + \\
\hline Tween 80 & - \\
\hline Urea & - \\
\hline Aesculin & - \\
\hline$\beta$-Galactosidase & + \\
\hline Nitrate reduction & - \\
\hline \multicolumn{2}{|l|}{ Assimilation of: } \\
\hline Glucose & + \\
\hline Arabinose & - \\
\hline Mannose & - \\
\hline$N$-acetylglucosamine & - \\
\hline Maltose & + \\
\hline Caprate & + \\
\hline Mannitol & + \\
\hline Gluconate & + \\
\hline Malate & + \\
\hline Citrate & + \\
\hline Adipate & - \\
\hline Phenylacetate & - \\
\hline \multicolumn{2}{|l|}{ Growth at: } \\
\hline $25^{\circ} \mathrm{C}$ & + \\
\hline $37^{\circ} \mathrm{C}$ & - \\
\hline \multicolumn{2}{|l|}{ Growth in: } \\
\hline $7 \% \mathrm{NaCl}$ & + \\
\hline \multicolumn{2}{|l|}{ Pigment production } \\
\hline in King's B medium & - \\
\hline \multicolumn{2}{|l|}{ Sensitivity to: } \\
\hline Penicillin & - \\
\hline Streptomycin & + \\
\hline Chloramphenicol & + \\
\hline Tetracycline & - \\
\hline Novobiocin & - \\
\hline Polymyxin B & + \\
\hline
\end{tabular}

+ , Positive reaction; - , negative reaction.

at $\delta_{\mathrm{H}} 2.23$ and $2.17 .^{\left.{ }^{1}\right)}$ After $O$-deacetylation, the disappearance of these signals was observed. No ${ }^{1} \mathbf{H}$ signal corresponding to carboxyethylidene substituent was observed. ${ }^{22)}$

After acid hydrolysis of the polysaccharide an amino sugar $\left(R_{\text {glc }}=0.77\right)$, uronic acid $\left(R_{\text {gle }}=\right.$ 0.92 ), and an amino acid were observed by paper chromatography. The amino sugar was identified 
Table 2. Fractionation of the polysaccharide by DEAE-cellulose column chromatography*

\begin{tabular}{cc}
\hline $\mathrm{NaCl}$ conc. $(\mathrm{M})$ & Product $(\mathrm{mg})$ \\
\hline 0 & 0 \\
0.2 & 3.8 \\
0.3 & 51.4 \\
0.4 & 434.5 \\
0.6 & 690 \\
0.8 & 12.6 \\
1.0 & 50 \\
20 & 3.9 \\
\hline Total & 5802 \\
\hline
\end{tabular}

* The crude polysaccharide preparation $(721.3 \mathrm{mg})$ was applied to DEAE-cellulose column as described in the text.

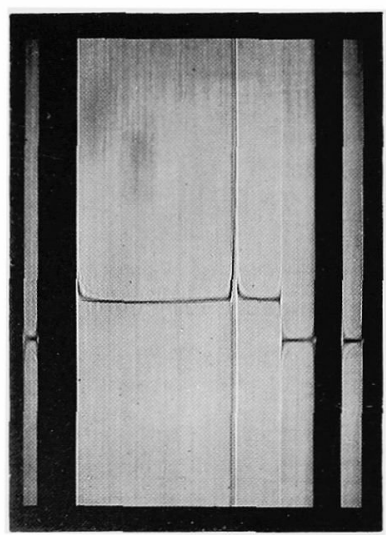

Fig. 2. The sedimentation pattern of the polysaccharide. Measurement was made in $0.1 \mathrm{M}$ $\mathrm{NaCl}$ solution $(2.5 \mathrm{mg} / \mathrm{m} /)$ at $25^{\circ} \mathrm{C}$. Photograph was taken $40 \mathrm{~min}$ after the maximum speed $(60,000 \mathrm{rpm})$ was obtained. The direction of sedimentation was from right to left.

as glucosamine by electrophoresis, HPLC (Fig. 5), and amino acid analyzer. The amino acid was identified as glutamic acid by amino acid analyzer. The glutamic acid liberated by acid hydrolysis of the polysaccharide and the authentic L-glutanic acid were destroyed by the enzyme L-glutamic acid dehydrogenase, whereas the authentic Dglutamic acid was unchanged. This indicates that the glutamic acid in the hydrolyzate has the L-absolute configuration.

Oligomer shown in the HPLC of the hydrolyzate of the polysaccharide (Fig. 5) was separated on an Amberlite IR 410 resin (formate). The acidic fraction obtained was homogeneous in electrophoresis and gave glucuronic acid and glucosamine on hydrolysis to a molar ratio of $1: 1$. Thus, the oligomer is an aldobiouronic acid with

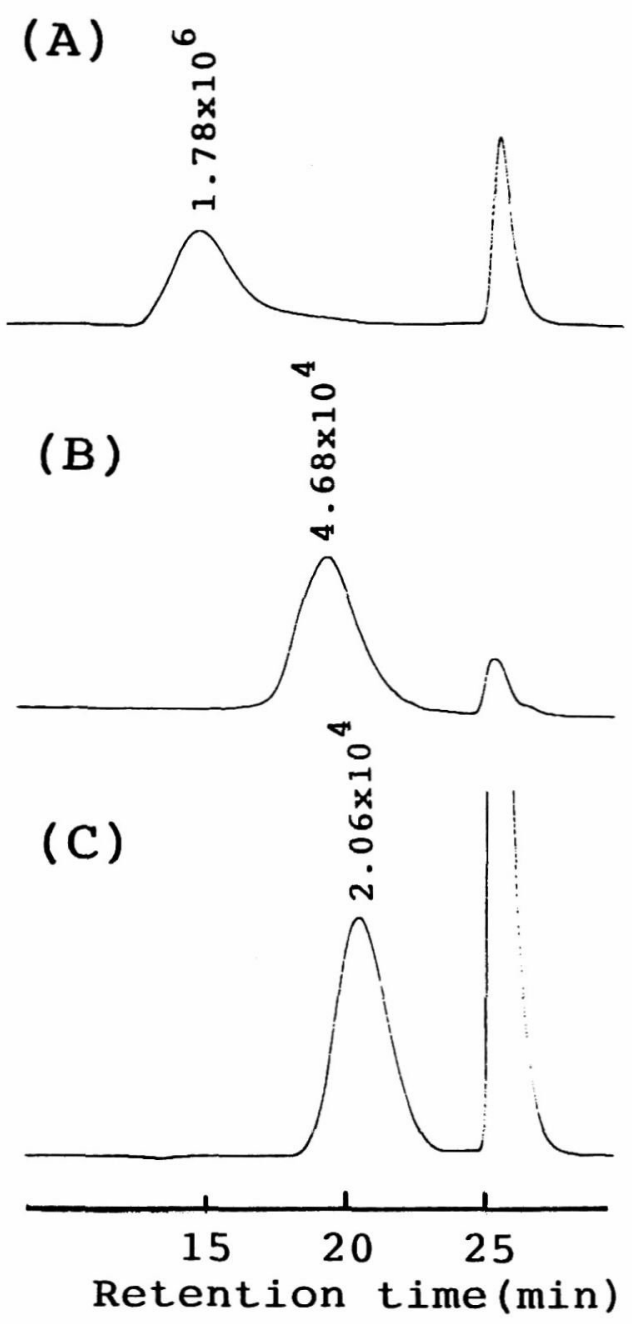

Fig. 3. GPC profiles of the polysaccharide. Molecular weights of the polysaccharide were calculated as described in the text. A, native polysaccharide; B, oxidation/reduction product; C, Smith hydrolysis product.

the structure of GlcUA-GlcN. The uronic acid was separated on an Amberlite IR-410 resin $\left(\mathrm{OH}^{-}\right.$form) from the acid hydrolyzate of the polysaccharide, followed by purification by preparative paper chromatography. Carboxyl reduction of this product gave glucose, indicating the presence of glucuronic acid in the polysaccharide. The glucose derived from glucuronic acid after carboxyl reduction was destroyed by D-glucose oxidase, indicating the D-configuration of the glucuronic acid.

The polysaccharide was hydrolyzed with various concentrations of $\mathrm{HCl}$, and the hydrolyzates were 


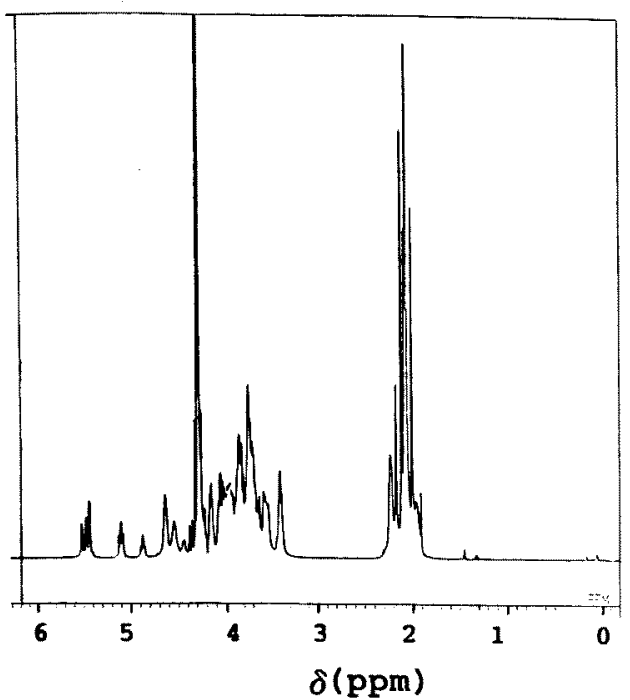

Fig. 4. 'H NMR spectrum of the polysaccharide in $\mathrm{D}_{2} \mathrm{O}$.

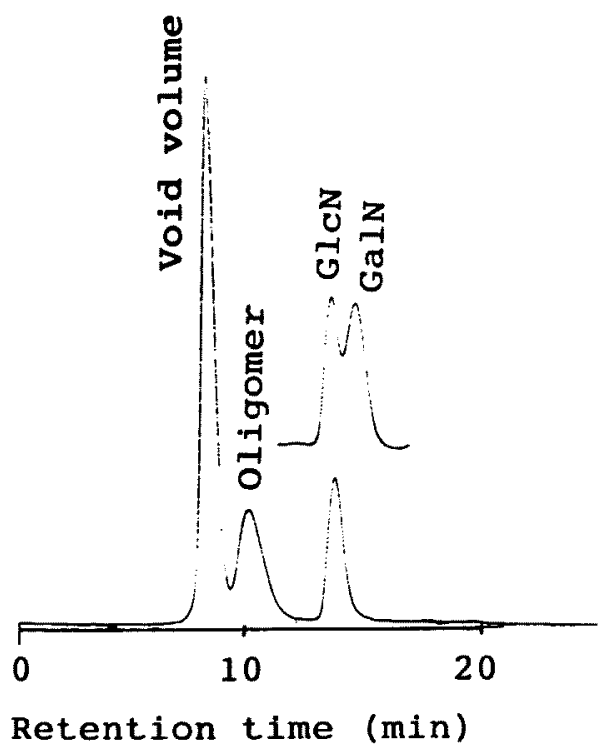

Fig. 5. Elution profiles of the hydrolyzates on a Wakopak WBT 130E column. The hydrolyzates and the authentic amino sugars were subjected to acetylation with pyridine-acetic anhydride, and then injected to HPLC. The peak with Rt 10.1 was collected to yield the purified product of the oligomer. GlcN, glucosamine; GalN, galactosamine; Oligomer, oligosaccharide.

analyzed for glucosamine and glutamic acid (Fig. 6). The liberation of these components occurred at high acid concentrations of $\mathrm{HCl}$. From the data obtained, hydrolysis with $4 \mathrm{~N}$

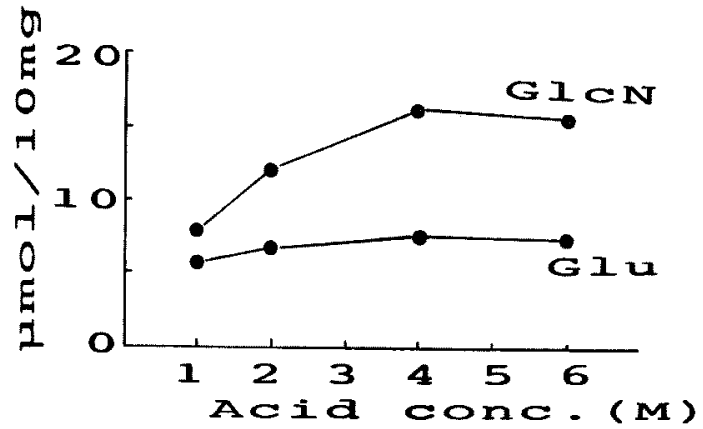

Fig. 6. Liberation of glucosamine and glutamic acid on hydrolysis of the polysaccharide. Hydrolysis was carried out with various $\mathrm{HCl}$ concentrations for $12 \mathrm{~h}$ at $100^{\circ} \mathrm{C}$. Components were expressed as $\mu \mathrm{mol}$ per $10 \mathrm{mg}$ of the polysaccharide. GlcN, glucosamine; Glu, glutamic acid.

$\mathrm{HCl}$ for $12 \mathrm{~h}$ at $100^{\circ} \mathrm{C}$ was adopted to estimate contents of glucosamine and glutamic acid.

From our investigations, it was indicated that the viscous substance produced by a marine Pseudomonas strain No. 42 was composed of glucosamine, glucuronic acid and glutamic acid as the constituent, suggesting a structure analogous to that of hyaluronic acid ${ }^{3)}$ containing glutamic acid. Hyaluronic acid was first isolated from bovine vitreous humour and later from the human umbilical cord and other connective tissues.2) Bacterial formation of hyaluronic acid was reported in cultures of Streptococcus pyogenes, ${ }^{1)}$ Pseudomonas aeruginosa, ${ }^{2)}$ and other streptococcal strains. ${ }^{23)}$ However, no amino acid-containing hyaluronic acid has been reported. These results suggest that the component of the present polysaccharide differs markedly from that of the alanine-containing mucopolysaccharide elaborated by marine $\boldsymbol{P}_{\text {seudomonas. }}{ }^{4}$

This polysaccharide preparation did not contain nucleic acids, proteins, pyruvic acids, or sulfates.

\section{Periodate Oxidation}

After being treated with periodate followed by $\mathrm{NaBH}_{4}$ the poly saccharide had a molecular weight of $4.68 \times 10^{4}$ (Fig. 3B). This differed greatly from that of the intact polysaccharide. The polymeric material remained after the Smith hydrolysis of the polysaccharide was found to be homogeneous according to electrophoresis, and its molecular weight was estimated to be $2.06 \times 10^{4}$ (Fig. 3C). This indicates that the polysaccharide was oxidized by periodate but the main chain of the polysaccharide was resistant 
to the periodate.

Further studies of the structure of this polysaccharide are in progress using the techniques of methylation, partial hydrolysis, and NMR spectrometry.

\section{Acknowledgments}

We are grateful to Dr. E. Miki and Dr. T. Tokuda of Kagawa University for operating the electron microscope.

\section{References}

1) W. A. Pierce, Jr, and A. G. C. White: Hyaluronic acid formation by Streptococcus pyogenes. Proc. Soc, Exp. Biol. Med., 87, 50-54 (1954).

2) G. J. Bonde, F. E. Carlsen, and D. E. Jensen: Production of hyaluronic acid by Pseudomonas acruginosa. Acta Pharmacol. Toxicol., 13, 205-212 (1957).

3) K. Lami: Mucopolysaccharides produced by a strain of Clostridium perfringens. J. Bacteriol., 83, 956-959 (1962).

4) S. Tandavanitj, S. Ishida, and K. Okutani: Isolation and characterization of an extraceliular mucopolysaccharide produced by a marine strain of Pseudomonas. Nippon Suisan Gakkaishi, 55, 2015-2019 (1989).

5) K. Okutani and S. Tandavanitj: Isolation and characterization of fucosamine-containing polysaccharide from a marine strain of Pseudomonas. Nippon Suisan Gakkaishi, 57, 2151-2156 (1991)

6) W. Gromska and H. Mayer: The linkage of lysine in the O-specific chains of Proteus mirabilis 1959. Eur. J. Biochem, 62, 391-399 (1976).

7) E. V. Vinogradov, W. Kaca, A. Shashkov, D. K. Pietrasik, A. Rozalski, Y. A. Knirel, and N. K. Kochetkov: The structure of Proteus mirabilis $03 \mathrm{O}$-specific polysaccharide containing $N$-(2-hydroxyethyl)-D-alanine. Eur. $J$, Biochem., 188, 645-651 (1990).

8) K. Okutani: Taxonomical studies of a polysaccharide-producing bacterium from sea cucumber, Stichopus japonicus, (SELENKA). Tech. Bull. Fac. Agr. Kagawa Univ., 36, 135140 (1985).

9) M. Dubois, K. A. Gilles, J. K. Hamilton, P. A. Rebers, and F. Smith: Colorimetric method for determination of sugars and related substances. Anal. Chem., 28, 350-356 (1956)

10) S. J. Stahl, K. R. Stewart, and F. D. Williams: Extracellular slime associated with Proteus mirabilis during swarming J. Bacteriol, 154, 930-937 (1983).

11) I. Miyamoto and S. Nagase: Simple method for the determenation of glucosamine and galactosamine using cellulose acetate electrophoresis. J. Biochem., 91, 1445-1447 (1982).

12) Z. Dische: A new specific color reaction of hexuronic acids. J. Biol. Chem., 167, 180-198 (1947).

13) O. H. Lowry, N. J. Rosebrough, A. L. Farr, and R, J. Randall: Protein measurement with the Folin phenol reagent. I. Biol. Chem., 103, 265-275 (1951).

14) N. J. Palleroni: Genus I. Pseudomonas, in "Bergey"s Manual of Systematic Bacteriology" (ed. by N. R. Krieg and J. G. Holt) Vol. 1, Williams and Wilkins, London, 1984, pp. 141-199.

15) U. Shimidzu: Identification of Marine Bacteria, in "Methads in Marine Bacteriology" (ed. by H. Kadota and N. Taga), Gakkai Shuppan Center, 1985, pp. 228-233 (in Japanese).

16) F. Gavini, B. Holmes, D. Izard, A. Beji, A. Bernigand, and E. Jakubczak: Numerical taxonomy of Pseudomonas alcaltgenes, $P$. pseudoalcaligenes, $P$. mendocina, $P$. stutzeri, and related bacteria. Int. J. Syst. Bact., 39, 135-144 (1989).

17) P. B. Bauman, R. D. Bowditeh, L. Bauman, and B. Beaman: Taxonomy of marine Pseudomonas species: $P$. stanier $\mathrm{sp}$. nov.; $P$. perfectomarina sp. nov., nom. rev.; $P$. nautica; and P. doudorottii. Imt. J. Syst. Bact, 33, 857-865 (1983).

18) L. Bauman, P. Bauman, M. Mandel, and R. D. Allen: Taxonomy of aerobic marine eubacteria. J. Bacteriol., 110, $402-429$ (1972).

19) Y. A. Knirel, V, V. Dashunin, A. S. Shashkov, N. K. Kochetkov, B. A. Dmitriev, and I. L. Hofman: Somatic antigens of Shigella: structure of the $O$-specific polysaccharide chain of the Shigella dysenteriae type 7 lipopolysaccharide. Corbohydr, Res., 179, 51-60 (1988).

20) P. B. Helander, L. Kenne, B. Lindberg, K. Peterson, and R. Unger: Structural studies of two capsular polysaccharides elaborated by different strains of Haemophilis influenzae type e. Carbohydr. Res., 88, 77-84 (1981).

21) E. Katzenellenbogen, I. Ekiel, and E. Romanowska: The structure of the $O$-specific polysaccharide chain from Citrom bacter O23 lipopolysaccharide. Carbohydr. Res, 179, 349357 (1988).

22) K. Okutani and H. Kobayashi: The structure of an extracellular polysaccharide from a marine strain of Enterobacter. Nippon Suisan Gakkaishi, 57, 1947-1956 (1991).

23) K. Takayama: Hyaluronic acid-its production and application. Kagakuto Seibutsu, 26, 308-315 (1988) (in Japanese). 